\title{
THE EFFECT OF ACUPRESSURE ON HYPEREMESIS GRAVIDARUM IN PREGNANT WOMEN: A META ANALYSIS
}

\author{
Alfira Fitriana), Agus Kristiyanto'), Hanung Prasetya $^{3)}$ \\ 1)Masters Program in Public Health, Universitas Sebelas Maret \\ 2)Faculty of Sport Education, Universitas Sebelas Maret \\ 3)Health Polytechnics, Ministry of Health Surakarta
}

\begin{abstract}
Background: Nausea and vomiting are common complaints during early pregnancy. Many pharmacological treatments are available for hyperemesis, but concerns about their effect on fetal outcomes make many healthcare providers and pregnant women avoid or minimize the use of medications and prefer non-pharmacological therapies, such as acupressure. The purpose of this study was to determine the effects of acupressure on hyperemesis gravidarum in pregnant women.

Subjects and Method: A systematic review and meta analysis study was carried out using PRISMA flow diagram. Articles collection was obtained from Science Direct, PubMed, Google Scholar databases, which published from year 2005 to 2020 . Keywords used accupresure OR pressure OR "accupuncture point" AND "hyperemesis gravidarum" OR nausea OR vomitting AND "randomized controlled trial". Quantitative data were assessed using Review Manager 5.3 (RevMan 5.3) software.

Results: 9 articles showed that acupressure was effective to reduce hyperemesis gravidarum with high heterogeneity between experiments $\left(I^{2}=83 \%\right.$; $\left.<<0.001\right)$. This meta-analysis used random effect model (REM). Pregnant women with acupressure therapy had hyperemesis gravidarum 0.8 units lower than those without acupressure therapy (SMD $=-0.84 ; 95 \% \mathrm{CI}=-1.18$ to $-0.5 ; \mathrm{p}<0.001$ ).
\end{abstract}

Conclusion: Acupressure can reduce hyperemesis gravidarum in pregnant women.

Keywords: acupressure therapy, hyperemesis gravidarum, pregnant women

\section{Correspondence:}

Alfira Fitriana. Masters Program in Public Health, Universitas Sebelas Maret. Jl. Ir. Sutami 36A, Surakarta 57126, Central Java. Email: firafitriana01@gmail.com . Mobile: 085812071211. 